\title{
The Investigation of the Transformational Leadership Style Managers and Impact on the Financial Managerial Performance With the Modern Distributed Graph Analysis and Parallel Coordinates Algorithm in the United States
}

\author{
Karina Kasztelnik \\ Tennessee State University \\ Abdulraham Al-ahmadi \\ Scientific Research Consulting
}

This study introduces the application of parallel coordinates to accounting information and business science, illustrating the utility of our tools to visualize and explore different types of multivariate data. Prior studies have not been able to confirm earlier findings showing the leadership research results with the distributed graph analysis for the accounting or business decision. We offer a novel demonstration of how parallel coordinates provide a practical alternative to current data-driven solutions in the business and accounting toolboxes for visualizing and exploring multivariate data, identifying causal relationships, and communicating modern business science via the advanced interactive, web-based application. Modern exploratory digital analysis of business leadership, job performance, job satisfaction requires specialize tools to identify associations among variables. The results of the modern distributed graph analysis show better understanding a transformational leadership style affects employee satisfaction and performance and how may relate to improving business management and outcomes within the company with Artificial Intelligence Business Solution.

Keywords: leadership, HR, finance, job satisfaction, job performance, parallel coordinates, clustering, data visualization, distributed graph analysis, exploratory data analysis, business science communications

\section{INTRODUCTION}

As data sets become increasingly complex in any business discipline, we require more effective ways to display, analyze, filter and interpret all information that we contained within them. We examined the transformational leadership style mangers and impact on the financial managerial performance business companies in the United States.

Our data-driven algorithm works efficient as the new discovered engineered systems for parallel graph analytics algorithm in leadership business along with managerial finance. Particularly on nontraditional architectures, surveys and other research instruments, and incorporating graph analytics into the larger ecosystem of parallel computing are the current challenges and this is a modern rapidly growing research science area around the World. 
The theoretical framework upon which this study is constructed is SDT (Deci et al., 2017; Ryan \& Deci, 2000) which is identified in the literature as one of the most effective theoretical frameworks for investigations of psychological needs (Greguras \& Diefendorff, 2009). Self-determination theory and transformational leadership are the two important theories that serve as the backbone of this research. Kanat-Maymon et al. (2020) proposed the integration of the two theories into a single theory. Just as transformational leadership is categorized into several dimensions, SDT is also a multi-dimensional concept that includes three categories, autonomous motivation, controlled motivation, and amotivation. Autonomous motivation is characterized by an individual's self-motivation and free will. Autonomous motivation, as described in SDT, shares many characteristics with intrinsic motivation, as described in transformational leadership theory, with both referring to an inner motivation that leads individuals to take an action (Kanat-Maymon et al., 2020; Mathieu et al., 2020). Controlled motivation shares similarities with extrinsic motivation which are both guided by pressure-based, or external, factors that create motivation. Amotivation (i.e., failure to motivate) is similar to the laissez-faire leadership style that describes leaders who take a very passive, hands-off approach with the absence of intentions that lead to inaction. Although research by Kanat-Maymon et al. (2020) was focused on how these motivational factors can result in leaders that exhibit different leadership styles, this research is interested in how the skills of transformational leaders relate to employee satisfaction (Umadia \& Kasztelnik, 2020).

This information may inform future leaders of small businesses on the desired leadership style for achieving company goals. This study also utilizes transformational leadership, which mediates the job demands and resources using both autonomous motivations as well as controlled motivation to reduce psychological strain and increase job attitudes and performance (Fernet et al., 2015). The use of SDT is preferred in this research since it established three collective human needs, autonomy, competence, and relatedness. Personal growth and peak performance are only possible, according to SDT, if the three universal human needs are fulfilled. In the context of this study, leaders are critical influencers determining whether employees' psychological needs are met and what type of leadership is practiced plays a vital role in this process (Deci et al., 2017). By incorporating SDT with transformational leadership theory, this study suggests a correlation between employee attitudes and feelings as specifically outlined in the research questions and transformational leadership (Delanoy \& Kasztelnik, 2020). This study may contribute to filling a gap in the literature, with Wang and Poutziouris (2010) describing current knowledge of this complex topic as immature and confusing, by empirically investigating the manager's assessment of their level of performance or comfort with transformational leadership as applied in small businesses by examining the connection between managers' adoption of transformational leadership and potential benefits to employee job performance.

\section{NATURE OF THE STUDY}

This distributed graph quantitative study will examine the effect of the predictor variable, transformational leadership style, on the criterion variable, employee satisfaction, as listed in the research questions and measured through the use of surveys. This will provide a numeric measurement of the strength of relationships between each of the variables (Kasztelnik \& Delany, 2021). Specifically, idealized influence attributed (IIA), idealized influence behavioral (IIB), inspirational motivation, intellectual stimulation, and individualized consideration are all components that collectively measure the IV of transformational leadership style. Transformational leadership style will be measured using an online survey that asks managers about the nature of their leadership skills (Ismail et al., 2010). The DV is employee satisfaction, which refers to satisfaction with different aspects of their job, such as ability utilization, creativity, and supervision. Employee satisfaction will be measured using the MSQ, an online 20 scale survey with 100 questions about their job satisfaction (Weiss et al., 1967). Both scales have been shown to have validity as measurement tools (Ismail et al., 2010; Weiss et al., 1967).

This research will also measure several covariates, including employee performance, employee turnover rate, and workplace environment. The employee job performance (EJP) scale, a 13-item 
questionnaire that assesses job time, job quality, and job quantity, will be administered to quantify employee job performance (Na-Nan et al., 2018).

One aspect of the study that is an assumption is that participants will respond to questionnaires with honesty and without bias, as is the case any time questionnaires are used, rather than responding with what the participants think the researcher wants, which is referred to as response bias ( $\mathrm{Ng}$ et al., 2016). Managers could misreport their transformational leadership style when self-reporting their behaviors. The second assumption is that the measurement instruments, the transformational leadership scale by Ismail et al., (2010) and MSQ, are both appropriate scales for this research and its questions (Weiss et al., 1967). Fortunately, both of these instruments are reliable and valid scales for measuring transformational leadership style and employee satisfaction, respectively (Ismail et al., 2010; Weiss et al., 1967). The third assumption is that the responses to the surveys are representative of all small businesses in Virginia. Although the Small Business Supplier Diversity Agency provides an online directory of businesses that are certified by the Commonwealth of Virginia, there may be businesses that have not gotten certification and therefore will not be part of this research.

\section{RESEARCH QUESTION}

RQ1: What characteristics of transformational leadership style do managers and impact on the job financial managerial performance in the United States?

$\boldsymbol{H}_{0}$ : There are no statistically significant results for any characteristics of transformational leadership style do managers and impact on the job financial managerial performance in the United States

$\boldsymbol{H}_{1}:$ There are statistically significant results for characteristics of transformational leadership style do managers and impact on the job financial managerial performance in the United States

RQ2: What is the relationship between job satisfaction (activities) and transformational leadership (New Ideas) and impact on the job financial managerial performance in the United States?

$H_{0:}$ There is no the relationship between job satisfaction (activities) and transformational leadership (New Ideas) and impact on the job financial managerial performance in the United States

$\boldsymbol{H}_{1}$ : There is no the relationship between job satisfaction (activities) and transformational leadership (New Ideas) and impact on the job financial managerial performance in the United States

RQ3: What is the relationship between job satisfaction (social services) and job performance (authority) and impact on the job financial managerial performance in the United States?

$\boldsymbol{H}_{0}:$ There is no the relationship between job satisfaction (social services) and job performance (authority) and impact on the job financial managerial performance in the United States

$\boldsymbol{H}_{1}:$ There is no the relationship between job satisfaction (social services) and job performance (authority) and impact on the job financial managerial performance in the United States

RQ4: What is the relationship between job satisfaction (social services) and job satisfaction (security) and impact on the job financial managerial performance in the United States?

$\boldsymbol{H}_{0}:$ There is no the relationship between job satisfaction (social services and job satisfaction (security) and impact on the job financial managerial performance in the United States 
$\boldsymbol{H}_{1}$ : There is no the relationship between job satisfaction (social services) and job satisfaction (security) and impact on the job financial managerial performance in the United States

RQ5: What is the relationship between job satisfaction (achievement) and job satisfactions (recognition) and impact on the job financial managerial performance in the United States?

$\boldsymbol{H}_{0}:$ There is no the relationship between job satisfaction (achievement) and job satisfactions (recognition) and impact on the job financial managerial performance in the United States

$\boldsymbol{H}_{1}:$ There is no the relationship between job satisfaction (achievement) and job satisfactions (recognition) and impact on the job financial managerial performance in the United States

We used the visual clustering in parallel coordinates to describe the characteristics of transformational leadership. Data Collection come from the survey that was sent to our recruited participants to the study. 


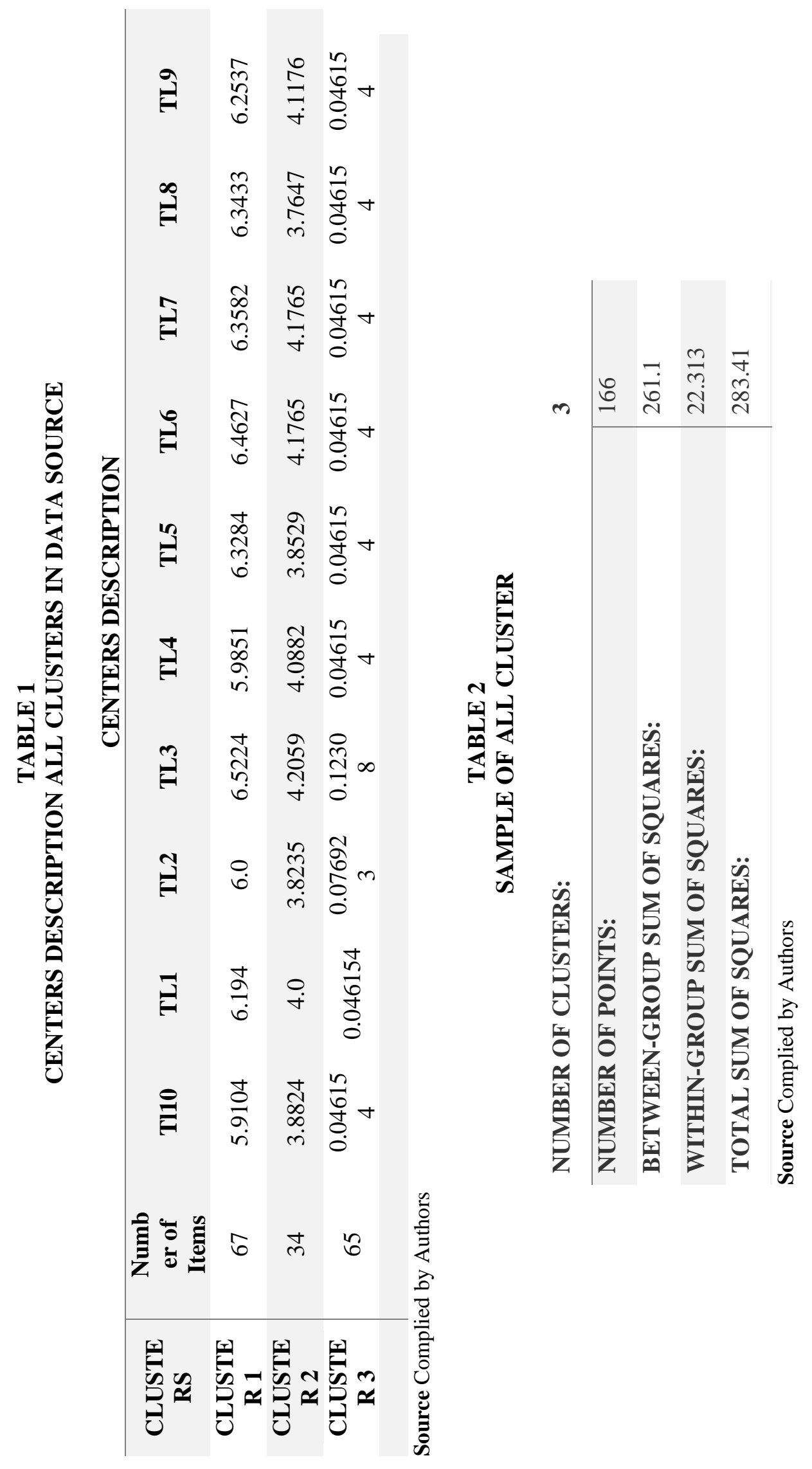




\section{TABLE 3}

ANALYSIS OF VARIANCE

\begin{tabular}{c|cccccc}
\multicolumn{1}{c}{} & \multicolumn{3}{c}{ MODEL } & ERROR \\
\hline VARIABLE & F-statistic & p-value & Sum of Squares & DF & Sum of Squares & DF \\
TL6 & 76.48 & 0.0 & 28.14 & 2 & 29.99 & 163 \\
TL8 & 76.28 & 0.0 & 26.85 & 2 & 28.69 & 163 \\
TL3 & 76.1 & 0.0 & 27.96 & 2 & 29.94 & 163 \\
TL9 & 75.81 & 0.0 & 26.41 & 2 & 28.39 & 163 \\
TL5 & 75.73 & 0.0 & 26.78 & 2 & 28.82 & 163 \\
TL7 & 75.56 & 0.0 & 27.3 & 2 & 29.45 & 163 \\
TL10 & 74.54 & 0.0 & 23.56 & 2 & 25.76 & 163 \\
TL2 & 74.3 & 0.0 & 23.92 & 2 & 26.24 & 163 \\
TL1 & 73.11 & 0.0 & 25.83 & 2 & 28.8 & 163 \\
TL4 & 72.58 & 0.0 & 24.33 & 2 & 27.32 & 163
\end{tabular}

Source Complied by Authors

\section{FIGURE 1 \\ TRANSFORMATIONAL LEADERSHIP SCALE AND MEASUREMENT - ALL THREE CLUSTERS}

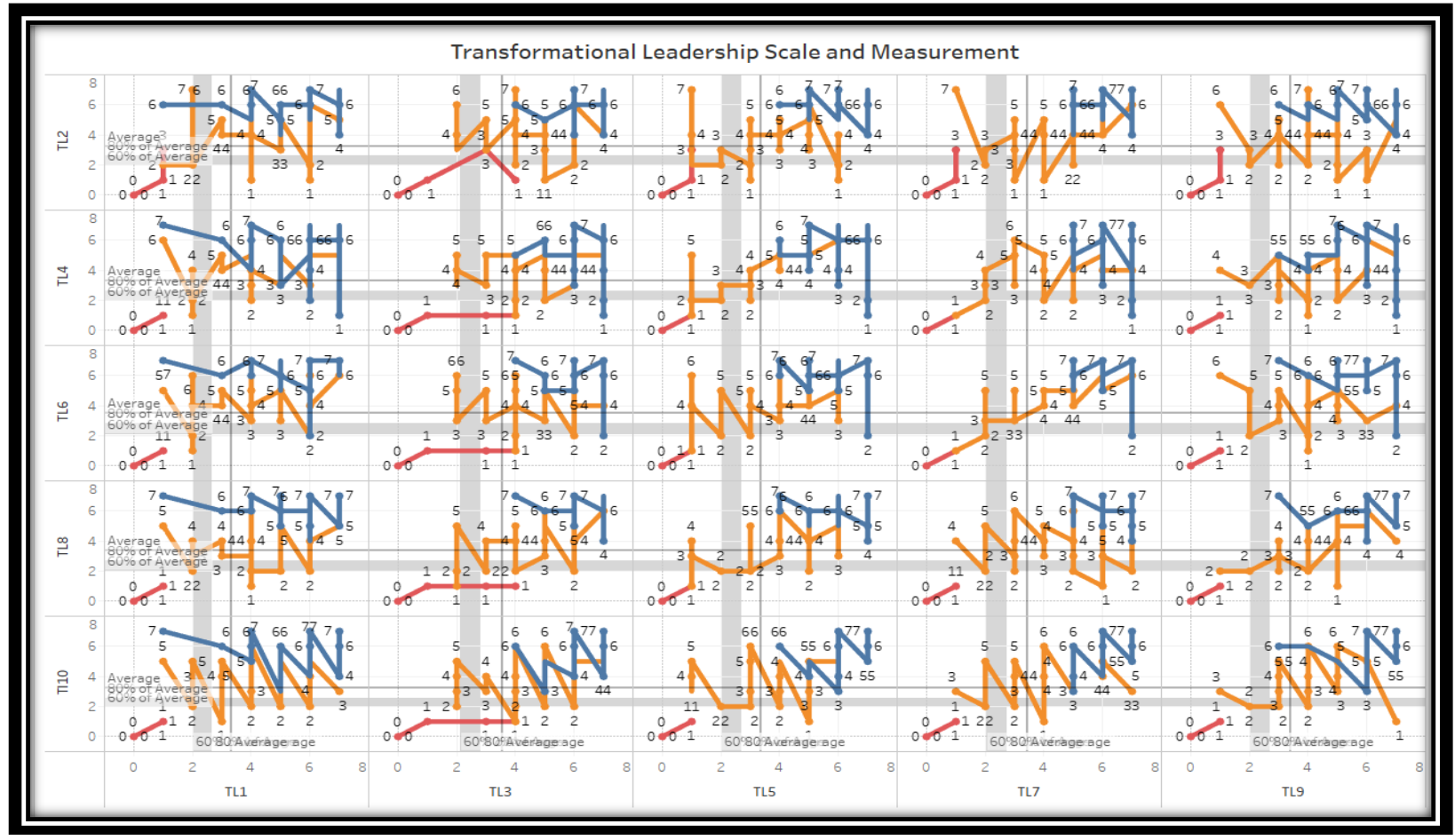

Legend:

TL1 - Excellence in others is the essence of leadership; TL2 - Spends time teaching and coaching; TL3 - Considers moral and ethical consequences; TL4 - Views me as having different needs, abilities, and aspirations;

TL5 - Listens to my concerns; TL6 - Encourages me to perform; TL7 - Increases my motivation

TL8 - Encourages me to think more creatively; TL9 - Sets challenging standards; TL10 - Gets me to rethink neverquestioned ideas; Cluster 1 - Blue Color; Cluster 2 - Orange; Cluster 3 - Red;

Source Complied by Authors 


\section{Legend:}

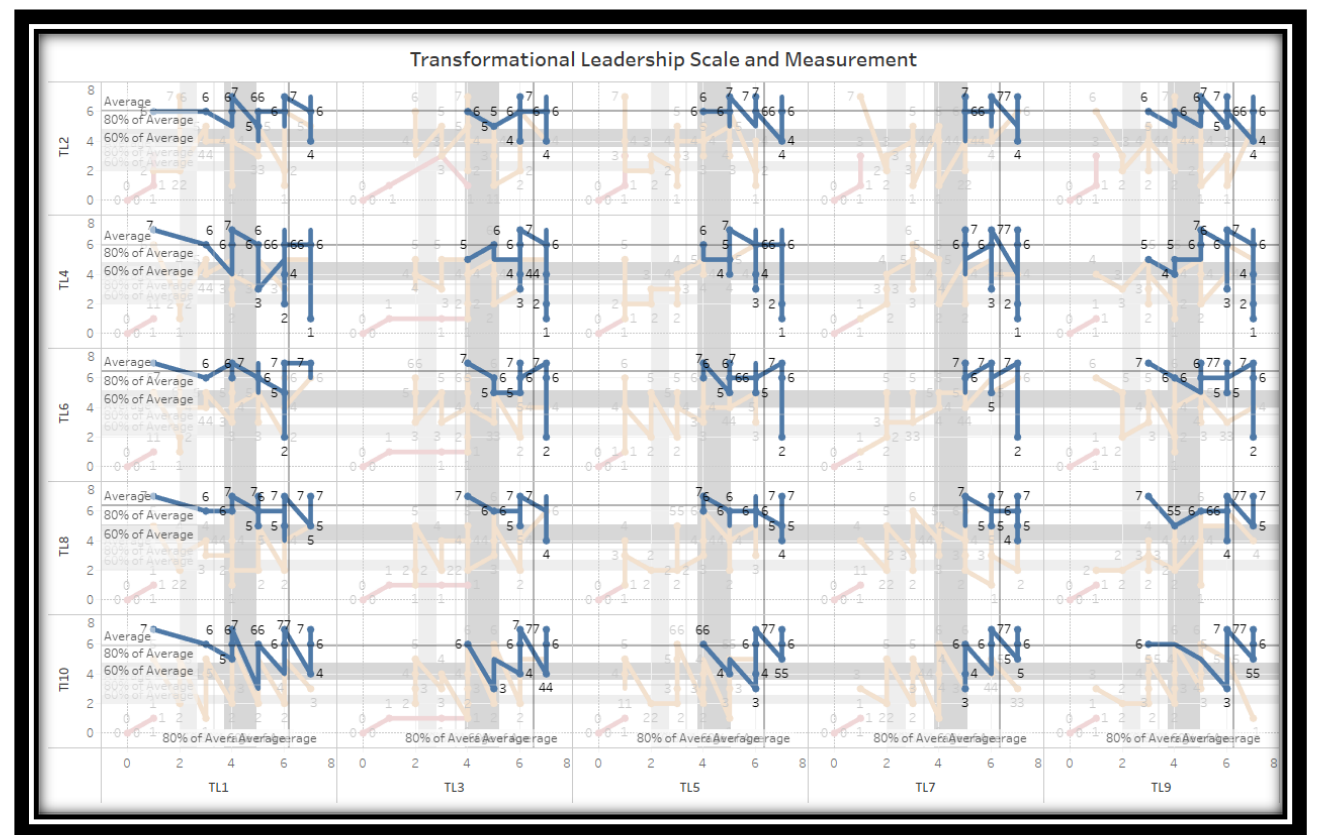

TL1 - Excellence in others is the essence of leadership; TL2 - Spends time teaching and coaching; TL3 - Considers moral and ethical consequences; TL4 - Views me as having different needs, abilities, and aspirations;

TL5 - Listens to my concerns; TL6 - Encourages me to perform; TL7 - Increases my motivation

TL8 - Encourages me to think more creatively; TL9 - Sets challenging standards; TL10 - Gets me to rethink neverquestioned ideas; Cluster 1 - Blue Color;

Source Complied by Authors

$\underline{\text { Result of Cluster } 1 \text { Observation: }}$

Top Category is TL7 - Increases my motivation $-70 \%$ responses, then TL6 - Encourages me to perform $-30 \%$ responses 
FIGURE 3

TRANSFORMATIONAL LEADERSHIP SCALE AND MEASUREMENT - CLUSTER 2

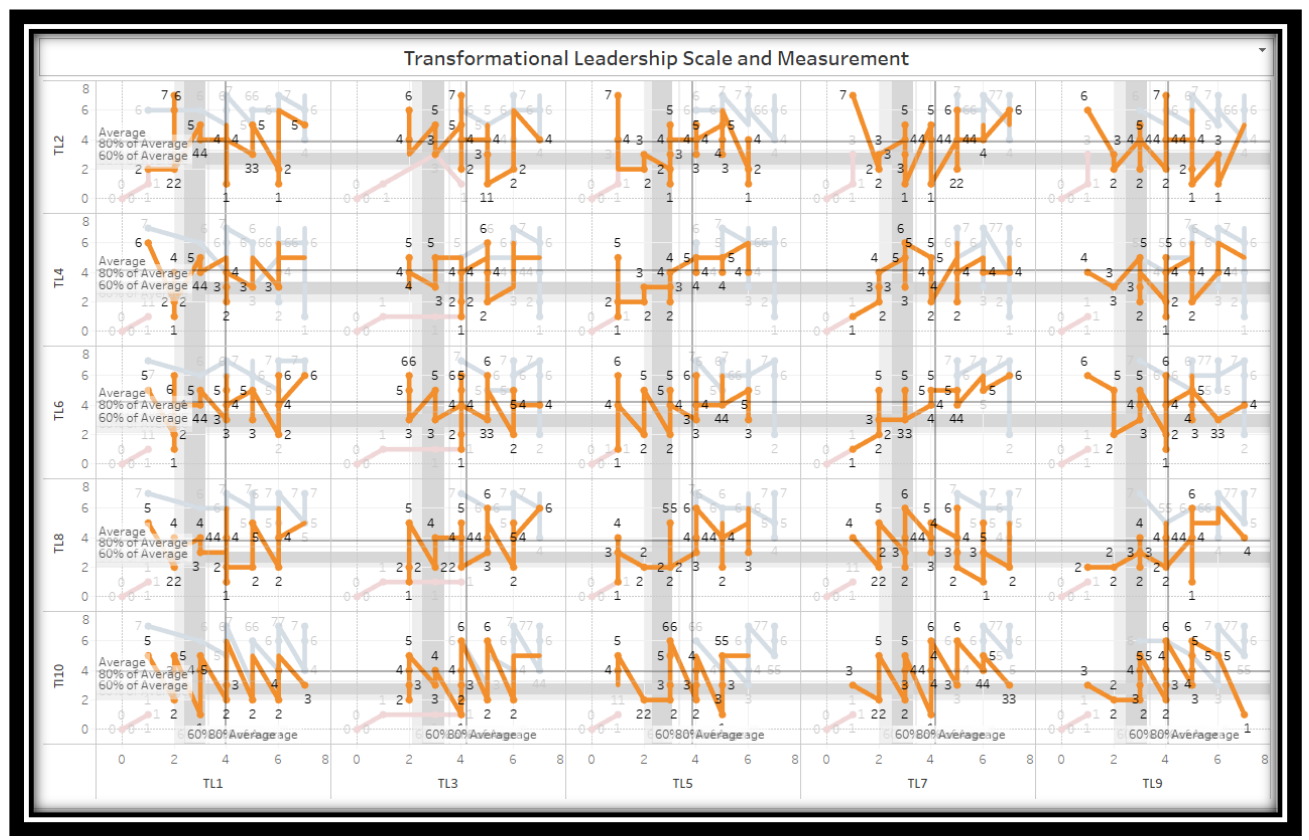

Legend:

TL1 - Excellence in others is the essence of leadership; TL2 - Spends time teaching and coaching; TL3 - Considers moral and ethical consequences; TL4 - Views me as having different needs, abilities, and aspirations;

TL5 - Listens to my concerns; TL6 - Encourages me to perform; TL7 - Increases my motivation

TL8 - Encourages me to think more creatively; TL9 - Sets challenging standards; TL10 - Gets me to rethink neverquestioned ideas; Cluster 2 - Orange;

Source Complied by Authors

\section{Result of Cluster 2 Observation:}

Top Category is TL1 - Excellence in others is the essence of leadership - 40\% responses, then TL4 Views me as having different needs, abilities, and aspirations $-30 \%$, then TL2 - Spends time teaching and coaching $-10 \%$ responses, then TL 7 - Increases my motivation - 10\% responses then TL3 - Considers moral and ethical consequences $-10 \%$ responses 
FIGURE 4

TRANSFORMATIONAL LEADERSHIP SCALE AND MEASUREMENT - CLUSTER 3

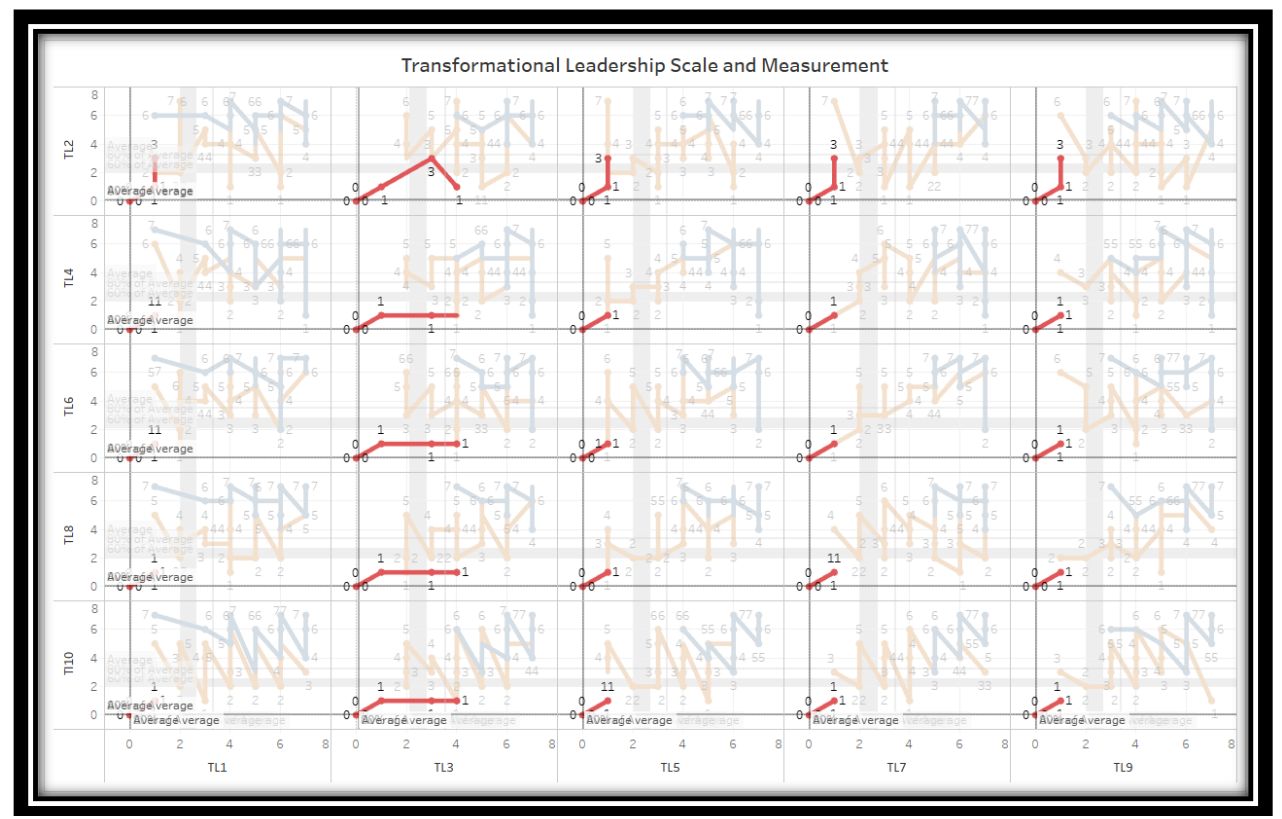

Legend:

TL1 - Excellence in others is the essence of leadership; TL2 - Spends time teaching and coaching; TL3 - Considers moral and ethical consequences; TL4 - Views me as having different needs, abilities, and aspirations;

TL5 - Listens to my concerns; TL6 - Encourages me to perform; TL7 - Increases my motivation

TL8 - Encourages me to think more creatively; TL9 - Sets challenging standards; TL10 - Gets me to rethink neverquestioned ideas; Cluster 3 - Red;

Source Complied by Authors

\section{Result of Cluster 3 Observation:}

Top Category is TL1 - Excellence in others is the essence of leadership - 80\% responses, then TL3 Considers moral and ethical consequences $-20 \%$ responses

Our research question 1 is what characteristics of transformational leadership style do managers and impact on the job financial managerial performance in the United States? A comparison of the three clusters reveals that the transformational leadership has the following characteristics: a) increases our motivation (70\% responses); b) excellence in others (40\% responses). The figures above illustrate the proportion of different clustering categories of our new discover characteristics transformation leadership. Our new discover model encourages leaders to demonstrate the increased motivation, excellence in others as most important part of the leadership style with the impact on the financial managerial performance per our survey. This is the first study of substantial transformation leadership which examines all components leadership with the parallel coordinate's algorithm.

Our next results respond to the rest of research questions in this distributed graph quantitative research study. 


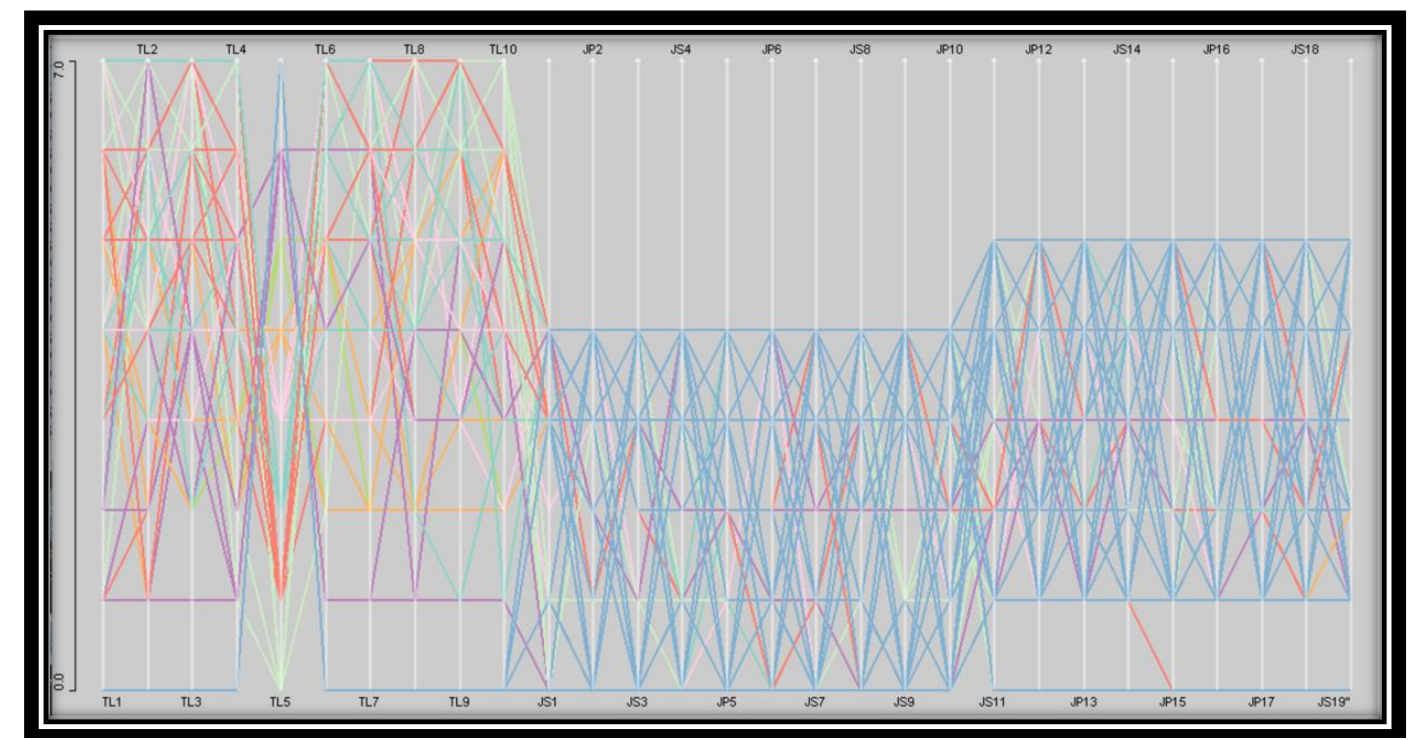

Legend:

TL1 - Excellence in others is the essence of leadership; TL2 - Spends time teaching and coaching; TL3 - Considers moral and ethical consequences; TL4 - Views me as having different needs, abilities, and aspirations;

TL5 - Listens to my concerns; TL6 - Encourages me to perform; TL7 - Increases my motivation

TL8 - Encourages me to think more creatively; TL9 - Sets challenging standards; TL10 - Gets me to rethink neverquestioned ideas; JS1 - Job Satisfaction - Activity; JP2 - Job Performance - Independence; JS3 - Job Satisfaction Variety; JS4 - Job Satisfaction - Social Status; JP5 Job Performance - Supervision - Human Relations) JP6 Job Performance -Supervision - Technical; JS7 - Job Satisfaction -Moral Values; JS8 - Job Satisfaction -Security. JS9 - Job Satisfaction -Social Services; JP10 Job Performance -Authority; JS11 - Job Satisfaction -Ability Utilization; JP12 Job Performance - Company Policies and Practices; JP13 Job Performance -Compensation; JP14 - Job Satisfaction -Advancement; JP15 Job Performance - Creativity; JP16 Job Performance -Working Conditions; JP17 Job Performance - Co-workers; JP18 - Job Satisfaction -Recognition; JP19 - Job Satisfaction - Achievement.

Source Complied by Authors

Result of Parallel Coordinates Observation:

Our parallel coordinate plot is scaled to have the same scales on all 29 axes. It has been observed on the Figure 5 that the variables JS7, JS8, JS9, JS14, JS15 show a strong positive relationship. It has been noted that the variables JS11, JS10 show a moderate positive relationship. Finally, It has been shown that the variables JS3, JS4, JS5, JS6, JP12, JP13, JP16, JP17, JS18, JS19 show a very strong positive relathionship within all existing variables. We are going to look into the model more deep and work within the two axes selected for our futher analysis. We selected for the future deep investigation from the original full graph the following variables: JS9 - Job Satisfaction (Social Services); JS8 - Job Satisfaction (Security); JS9 - Job Satisfaction (Social Security); JP10 - Job Performance (Authority); JS19 - Job Satisfaction (Achievement); JS18 - Job Satisfaction (Recognition); JS1 - Job Satisfaction (Activites); TL10 - Transformational Leadership (New Ideas). Our graph structure is very diverse and has a major impact on the performance of graph analytics algorithms. 
FIGURE 6

PARALLEL COORDINATES IN THE DISTRIBUTED GRAPHICAL VISUALIZATION VARIABLES THAT RESPOND TO OUR MAJOR RESEARCH QUESTIONS IN THIS STUDY

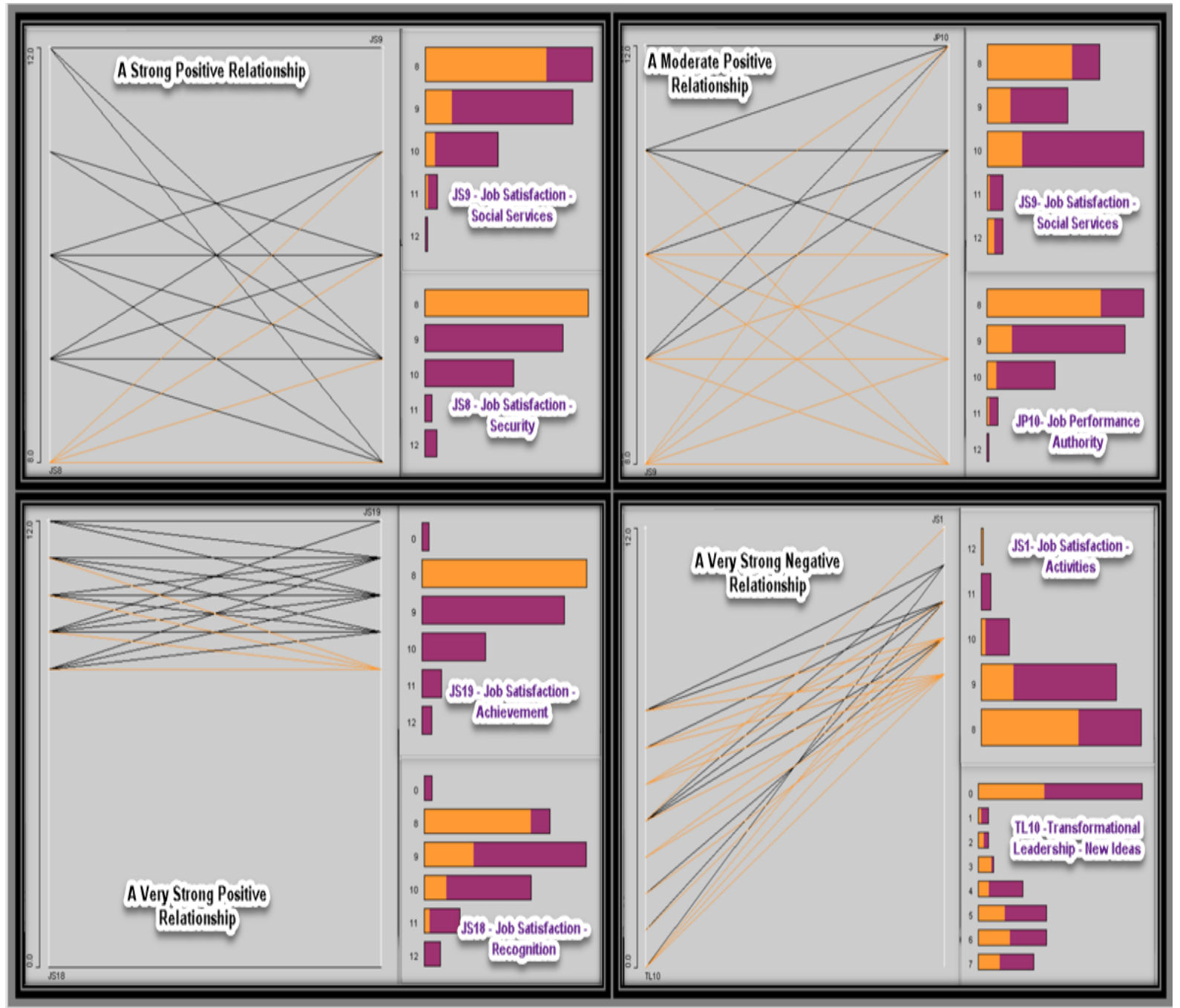

Source Complied by Authors

Research Question 2: What is the relationship between job satisfaction (activities) and transformational leadership (New Ideas) and impact on the job financial managerial performance in the United States?

The Figure 6 shows the intercorrelations among the two measures of activities and new ideas. We found a very strong negative relationship based on the graph on the level of (0.0346). From the plot, it may be seen that often there are also low values in the variables of activities and new ideas. Previous studies have failed to find any correlation between job satisfaction (activities) and transformational leadership (new ideas) and impact on the job financial managerial performance in the United States. Our findings show that the lack of new ideas lead to the decreasing job satisfaction within our employees. The opposite effect exists when the job satisfaction decreases then our transformation leadership decreases as well and become not effective for our business. 
Research Question 3: What is the relationship between job satisfaction (social services) and job performance (authority) and impact on the job financial managerial performance in the United States?

The Figure 6 displays the graph of the relationship between social services and authority. We found a moderate positive relationship based on the graph on the level of 0.3740 . What can be clearly seen in this figure is the steady moderate positive increase of social services and authority and significant impact on the job financial managerial performance company. Our findings show that the increase job performance (authority) increases the job satisfaction (social services). The opposite effect exists when the job satisfaction increases (social services) increases as well and become moderate effective for our business.

Research Question 4: What is the relationship between job satisfaction (social services) and job satisfaction (security) and impact on the job financial managerial performance in the United States?

The Figure 6 presents the results obtained from the analysis of social services and security. We found a strong positive relationship based on the graph on the level of 0.4465 . The results of the parallel coordinates graph can be seen in Figure 6 with a strong positive increase social services along with security. Our findings show that social services increase the security and security increases social services.

Research Question 5: What is the relationship between job satisfaction (achievement) and job satisfactions (recognition) and impact on the job financial managerial performance in the United States?

The Figure 6 provides an overview of the relationship between achievement and recognition. We found a very strong positive relationship based on the graph on the level of 0.8379 . The discovered pattern in Figure 6 is clearly ssen that is, the values of achievement increase as the value of recognition. What stands out in this figure 6 is the dominance of a very strong positive relationship both variables achievement, and performance as a part of the employee job satisfactions.

\section{SIGNIFICANCE TO THEORY}

The importance of this study for advancing theory is the contribution it will make by expanding the literature and current knowledge of transformational leadership style and employee satisfaction, which would benefit from the further empirical investigation (Wang and Poutziouris, 2010). Although prior research has shown that this relationship exists in large industries like nursing, little focus has been placed on transformational leadership style and employee satisfaction in the small businesses industry as the current study does (Choi et al., 2016). Manager's adoption of transformational leadership will be measured against employee satisfaction, which can offer benefits to employee job performance. The results of this study may be valuable for adding to the body of knowledge, which is lacking much information, on the relationship between transformational leadership and employee satisfaction, with an emphasis on small businesses in Virginia. This will serve to increase scientific knowledge, inform managers and leaders on effective leadership skills, improve small business outcomes, and aid the state of Virginia and the US economy.

\section{SIGNIFICANCE TO PRACTICE}

The current study is significant for advancing practices in small businesses in Virginia to improve business outcomes. This is important since businesses with a workforce that is disengaged may face

disruption and increased costs due to nonproductive employees through higher turnover rates and costs for retraining, lower productivity, and may even result in poor psychological well-being and physical health (Yalabik et al., 2017). Research has shown that employee dissatisfaction with the leadership of their company results in dissatisfaction and lack of motivation that typically negatively impacts job performance that can disrupt business and cause considerable costs (Fulmer \& Ostroff, 2017; Pittino et al., 2016; Yalabik et al., 2017). Considering that small businesses (those under 500 employees) are responsible for $52.7 \%$ of 
all jobs, with $30.7 \%$ of all employees in the United States working for businesses between 20-499 employees, this is a critical component of the economy that cannot be ignored (Dilger, 2019). Most existing literature indicates a connection between transformational leadership style and employee attitudes and performance (Aga et al., 2016; Bass, 1998; Cheng et al., 2016). However, Wang and Poutziouris (2010) observed that research on the management of small and medium-sized enterprises is inadequate and requires further investigation. This research on transformational leadership and employee satisfaction will offer a new perspective by examining this relationship in the small business sector of Virginia whereas much of the existing research focuses on large businesses such as hospitals, often in regions outside of the US. The results of this research will serve to inform small business managers in Virginia on how to enhance employee performance using a transformational leadership style to excel in business.

\section{SIGNIFICANCE TO SOCIAL CHANGE}

Transformational leaders inspire followers to accept and support the organization's vision while providing the direction required to attain established goals, often using individualized support (Podsakoff et al., 1996). A transformational leader also elicits feelings of trust and respect which encourages followers to accomplish more than they would in different circumstances. The current study is worth pursuing so that leaders can be informed on the best practices for positive interactions with employees that lead to better outcomes. This process typically involves followers changing existing attitudes and beliefs to accomplish a greater good than mere satisfaction with personal job performance. There is value in learning more about how transformational leaders help to create positive attitudes among employees that lead to increased job satisfaction and performance so that both individuals and businesses can experience positive outcomes. Transformational leaders provide a set of values and standards adopted by followers allowing individuals to become more well-rounded and concerned with organizational goals (Aga et al., 2016; Choi et al., 2016; Vatankhah et al., 2017). The results of this study can help small businesses in the US to make more informed decisions that will improve their chances of success. This research may have value beyond its current scope of small businesses in Virginia and may also serve as a starting point for other researchers that want to learn more about transformational leadership and employee satisfaction in small businesses in other regions of the US and other countries as well. Ultimately, this process creates positive change on many levels that followers also apply in their personal lives as they more clearly identify the significance of larger system functioning as opposed to individual attainment.

\section{CONCLUSION AND RECOMMENDATIONS}

Increased time and resources would help to expand upon the current research. This would allow a longer period for recruitment to increase the participant pool and therefore increase the sample size. Additional resources may have also made it possible to offer an incentive to participants for their time. This research was limited to small businesses in Virginia but widening the research to include small businesses in the U.S. could extend the generalizability and scope of the research. A different approach to the research design might be able to provide more detailed information about how transformational leadership style affects job performance and satisfaction.

This research consistently showed that there is a positive correlation between transformational leadership and job satisfaction and performance, with several having strong positive correlations. This supports the notion that the transformational leadership style is an important aspect of the business environment because it can affect employee performance and well-being (Deci et al., 2017). It could be valuable to examine whether differences in this relationship exist between small, medium, and large businesses, not only in Virginia but countrywide also.

While this research was conducted in the business setting, it would be valuable to examine this relationship in other situations where managerial and leadership skills are needed. Current theories of behavior suggest that industries such as healthcare and education might benefit from transformational 
leadership skills being used by leaders within the organization (Deci et al., 2017). This and future research on transformational leadership style can improve outcomes in small businesses and other organizations.

In this research paper, we introduce a new approach to use the machine learning algorithm into leadership, finance, management business discipline. We used the distributed graph data analytics with the parallel coordinate's algorithm followed by cluster detection to discover the new model transformational leadership. Nowadays, business disposes of an impressive number of statistical solutions but not the machine learning data-driven solutions as we used in this article.

\section{REFERENCES}

Aga, D.A., Noorderhaven, N., \& Vallejo, B. (2016). Transformational leadership and project success: The mediating role of team-building. International Journal of Project Management, 34(5), 806-818. https://doi.org/10.1016/j.ijproman.2016.02.012

Bass, B.M. (1998). Transformational leadership: Industrial, military and educational impact. Lawrence Earlbaum Associates, Publishers. Retrieved from https://psycnet.apa.org/record/1997-36282-000

Cheng, C., Bartram, T., Karimi, L., \& Leggat, S. (2016). Transformational leadership and social identity as predictors of team climate, perceived quality of care, burnout and turnover intention among nurses. Personnel Review, 45(6), 1200-1216. https://doi.org/10.1108/ PR-05-2015-0118

Deci, E.L. (1971). Effects of externally mediated rewards on intrinsic motivation. Journal of Personality and Social Psychology, 18(1), 105-115. https://doi.org/10.1037/h0030644

Deci, E.L., Connell, J.P., \& Ryan, R.M. (1989). Self-determination in a work organization. Journal of Applied Psychology, 74(4), 580-590. https://doi.org/10.1037/0021-9010.74.4.580

Deci, E.L., Olafsen, A.H., \& Ryan, R. (2017). Self-determination theory in work organizations: The state of a science. The Annual Review of Organizational Psychology and Organizational Behavior, 4, 19-43. https://doi.org/10.1146/annurev-orgpsych-032516-113108

Deci, E.L., \& Ryan, R.M. (1980a). Self-determination theory: When mind mediates behavior. The Journal of Mind and Behavior, 1(1), 33-43. Retrieved from http://www.jstor.org/stable/43852807

Deci, E.L., \& Ryan, R.M. (1980b). The empirical exploration of intrinsic motivational processes. Advances in Experimental Social Psychology, 13, 39-80. https://doi.org/10.1016/S00652601(08)60130-6

Delanoy, N. \& Kasztelnik, K. (2020). Business Open Data Analytics to Support Innovation Leadership and Management Decision in Canada. Business Ethics and Leadership, 4(2), 56-74. https://doi.org/10.21272/bel.4(2).56-74.2020

Dilger, R.J. (2019). Small business administration and job creation. In Small Business and Jobs: Research and Analysis in Brief. Congressional Research Service. Retrieved from https://sgp.fas.org/crs/misc/R41523.pdf

Fernet, C., Trépanier, S.G., Austin, S., Gagné, M., \& Forest, J. (2015). Transformational leadership and optimal functioning at work: On the mediating role of employees' perceived job characteristics and motivation. Work Stress, 29(1), 11-31. https://doi.org/10.1080/02678373.2014.1003998

Fulmer, C.A., \& Ostroff, C. (2017). Trust in direct leaders and top leaders: A trickle-up model. Journal of Applied Psychology, 102(4), 648-657. https://doi.org/10.1037/apl0000189

Ghasabeh, M.S., Soosay, C., \& Reaiche, C. (2015). The emerging role of transformational leadership. The Journal of Developing Areas, 49(6), 459-467. https://doi.org/10.1353/jda.2015.0090

Greguras, G.J., \& Diefendorff, J.M. (2009). Different fits satisfy different needs: Linking personenvironment fit to employee commitment and performance using self-determination theory. Journal of Applied Psychology, 94, 465-477. https://doi.org/10.1037/ a0014068

Hafeez, I., Yingjun, Z., Hafeez, S., Mansoor, R., \& Rehman, K.U. (2019). Impact of workplace environment on employee performance: Mediating role of employee health. Business, Management and Education, 17(2), 173-193. https://doi.org/10.3846/bme.2019.10379

Han, S.H., Seo, G., Yoon, S.W., \& Yoon, D. (2016). Transformational leadership and knowledge sharing. Journal of Workplace Learning, 28(3), 130-149. https://doi.org/10.1108/jwl-09-2015-0066 
Ismail, A., Mohamad, M.H., Mohamed, H.A., Rafiuddin, N.M., \& Zhen., K.W.P. (2010). Transformational and transactional leadership styles as a predictor of individual outcomes. Theoretical and Applied Economics Volume XVII, 6(547), 89-104. Retrieved from http://store.ectap.ro/articole/477.pdf

Kanat-Maymon, Y., Elimelech, M., \& Roth, G. (2020). Work motivations as antecedents and outcomes of leadership: integrating self-determination theory and the full range leadership theory. European Management Journal. https://doi.org/10.1016/j.emj.2020.01.003

Kasztelnik, K., \& Delany, N. (2020). Data Analytics and social media as the Innovative Business Decision Model with Natural Language Processing. Journal of Business and Accounting, 13(1), Fall 2020. Retrieved from http://asbbs.org/files/2020/JBA_Vol_13.1_Fall_2020.pdf

Lan, X.M., \& Chong, W.Y. (2015). The mediating role of psychological empowerment between transformational leadership and employee work attitudes. Procedia - Social and Behavioral Sciences, 172, 184-191. https://doi.org/10.1016/j.sbspro.2015.01.353

Ling, Q., Lin, M., \& Wu, X. (2016). The trickle-down effect of servant leadership on frontline employee service behaviors and performance: A multilevel study of Chinese hotels. Tourism Management, 52, 341-368. https://doi.org/10.1016/j.tourman.2015.07.008

Mathieu, J.E., Luciano, M.M., D’Innocenzo, L., Klock, E.A., \& LePine, J.A. (2020). The development and construct validity of a team processes survey measure. Organizational Research Methods, 23(3), 399-431. https://doi.org/10.1177/1094428119840801

Na-Nan, K., Chaiprasit, K., \& Pukkeeree, P. (2018). Factor analysis-validated comprehensive employee job performance scale. International Journal of Quality \& Reliability Management, 35(10), 2436-2449. https://doi.org/10.1108/ijqrm-06-2017-0117

Ng, H.S., Kee, D.M.H., \& Ramayah, T. (2016). The role of transformational leadership, entrepreneurial competence and technical competence on enterprise success of owner-managed SMEs. Journal of General Management, 42(1), 23-43. https://doi.org/10.1177/030630701604200103

Para-González, L., Jiménez-Jiménez, D., \& Martínez-Lorente, A.R. (2018). Exploring the mediating effects between transformational leadership and organizational performance. Employee Relations, 40(2), 412-432. https://doi.org/10.1108/ER-10-2016-0190

Pittino, D., Visintin, F., Lenger, T., \& Sternad, D. (2016). Are high performance work practices really necessary in family SMEs? An analysis of the impact on employee retention. Journal of Family Business Strategy, 7(2), 75-89. https://doi.org/10.1016/j.jfbs.2016.04.002

Ryan, R.M., \& Deci, E.L. (2000). Self-determination theory and the facilitation of intrinsic motivation, social development, and well-being. American Psychologist, 55(1), 68-78. https://doi.org/10.1037/0003-0066X.55.1.68

Top, M., Akdere, M., \& Tarcan, M. (2014). Examining transformational leadership, job satisfaction, organizational commitment and organizational trust in Turkish hospitals: Public servants versus private sector employees. The International Journal of Human Resource Management, 26(9), 1259-1282. https://doi.org/10.1080/09585192.2014.939987

Umadia, K. \& Kasztelnik, K. (2020). The Financial Innovative Business Strategies of Small to Medium Scale Enterprises in Developing Country and Influence for the Global Economy Performance. SocioEconomic Challenges, 4(3), 20-32. https://doi.org/10.21272/sec.4(3).20-32.2020

Vatankhah, S., Alirezaei, S., Khosravizadeh, O., Mirbahaeddin, S.E., Alikhani, M., \& Alipanah, M. (2017). Role of transformational leadership on employee productivity in teaching hospitals: Using structural equation modeling. Electronic Physician, 9(8), 4978-4984. https://doi.org/10.19082/4978

Wang, Y., \& Poutziouris, P. (2010). Leadership styles, management systems, and growth: Empirical evidence from UK owner-managed SMEs. Journal of Enterprising Culture, 18(3), 331-354. https://doi.org/10.1142/S0218495810000604

Weiss, D.J., Dawis, R.V., England, G.W., \& Lofquist, L.H. (1967). Manual for the Minnesota Satisfaction Questionnaire. Minnesota Studies in Vocational Rehabilitation, 22, 120. Retrieved 
from http://vpr.psych.umn.edu/sites/vpr.dl.umn.edu/files/monograph_xxii__manual_for_the_mn_satisfaction_questionnaire.pdf

Yalabik, Z.Y., Rayton, B.A., \& Rapti, A. (2017). Facets of job satisfaction and work engagement. Evidence-Based HRM: A Global Forum for Empirical Scholarship, 5(3), 248-265.

https://doi.org/10.1108/EBHRM-08-2015-0036 